\title{
Occurrence and Causes of Obesity in Albanian Young People
}

\author{
Eftiola Pojani, Msc. \\ PhD Candidate \\ "Vitrina" University, Department of Pharmacy, Faculty of Medical Sciences, Tirana, Albania \\ eftiolapojani@yahoo.com
}

\section{DOI:10.5901/mjss.2014.v5n19p33}

\begin{abstract}
Obesity is an abnormal accumulation of body fat, usually $20 \%$ or more over an individual's ideal body weight. More recent guidelines for obesity use a measurement called BMI (body mass index). BMI of 25.9-29 is considered overweight; BMI over 30 is considered obese. Measurements and comparisons of waist and hip circumference can also provide some information regarding risk factors associated with weight. The higher the ratio, the greater the chance for weight - associated complications. The amount of fat in a person's diet may have a greater impact on weight than the number of calories it contains. Obesity can also be a side effect of certain disorders and conditions, including: Cushing's syndrome, hypothyroidism, neurologic disturbances, such as damage to the hypothalamus, a structure that helps regulate appetite, consumption of such drugs as steroids, antipsychotic medications or antidepressants. The aim of this study was to understand the actual situations of weight in young people between the ages of eighteen and twenty-three and also to explain the reasons of weight gain in cases of obesity and overweight. In this study, the methodology applied was that of gathering information through a questionnaire. It was randomly distributed to a number of 200 students, 80 males and 120 females, from Korça and Tirana Universities. The participants ranged as it follows: 18 years old - 12\%, 19 years old - 18\%; 20 years old - 20,5\%; 21 years old - 18\%; 22 years old - $13 \%$ and 23 years old - 18,5\%. The subjects were also questioned about their life - style as it is considered as one of the important factors on rating the body weight. According to the results, it was found that only $1,5 \%$ of the respondents were obese; $13,5 \%$ were overweight, $73 \%$ had a normal weight and $12 \%$ were underweight. None of them declared to suffer from any diseases and a total of $77 \%$ indicated to live a moderate lifestyle.
\end{abstract}

Keywords: obesity, BMI, risk factor.

\section{Introduction}

More recent guidelines for obesity use a measurement called BMI. BMI of 25.9-29 is considered overweight; BMI over 30 is considered obese. Measurements and comparisons of waist and hip circumference can also provide some information regarding risk factors associated with weight. The higher the ratio, the greater the chance is for weight-associated complications. (Dale KS, McAuley KA, Taylor RW, Williams SM, Farmer VL, Hansen P, et al. 2009)

Obesity also increases the risk of developing a number of chronic diseases, including the following: Insulin resistance, Type 2 diabetes, High blood pressure, High cholesterol levels.

The mechanism for excessive weight gain is clear - more calories are consumed than the body burns, and the excess calories are stored as fat tissue. However, the exact cause is not as clear and likely arises from a complex combination of factors. Genetic factors significantly influence on how the body regulates the appetite and the rate at which it turns food into energy. Eating habits and patterns of physical activity also play a significant role in the amount of weight a person gains. Carbohydrates like cereals, bread, fruits, vegetables and protein are converted to fuel almost as soon as they are consumed. Most fat calories are immediately stored in fat cells, which add to the body's weight. (Jensen MD. 2011).

Obesity can also be a side effect of certain disorders and conditions, including: Cushing's syndrome, a disorder involving the excessive release of the hormone cortisol, hypothyroidism, neurologic disturbances, such as damage to the hypothalamus, a structure located deep within the brain that helps regulate appetite, consumption of such drugs as steroids, antipsychotic medications, or antidepressants. 
Diagnosis of obesity is made possible by observation and by comparing the patient's weight to ideal weight charts. (Schauer PR, Kashyap SR, Wolski K, 2012). Many doctors and obesity researchers refer to the body mass index (BMI), which uses a height-weight relationship to calculate an individual's ideal weight and personal risk of developing obesityrelated health problems.

\section{Methods}

In order to understand the actual situation according to body weight, a questionnaire was compiled and randomly distributed to a number of 200 students, 80 males and 120 females, from Korça and Tirana Universities.

The participants ranged as it follows: 18 years old - 12\%, 19 years old - 18\%; 20 years old - 20,5\%; 21 years old - 18\%; 22 years old - $13 \%$ and 23 years old - 18,5\%. The participants' age range is represented in the following chart: (Chart 1 )

\section{The participant's age range}

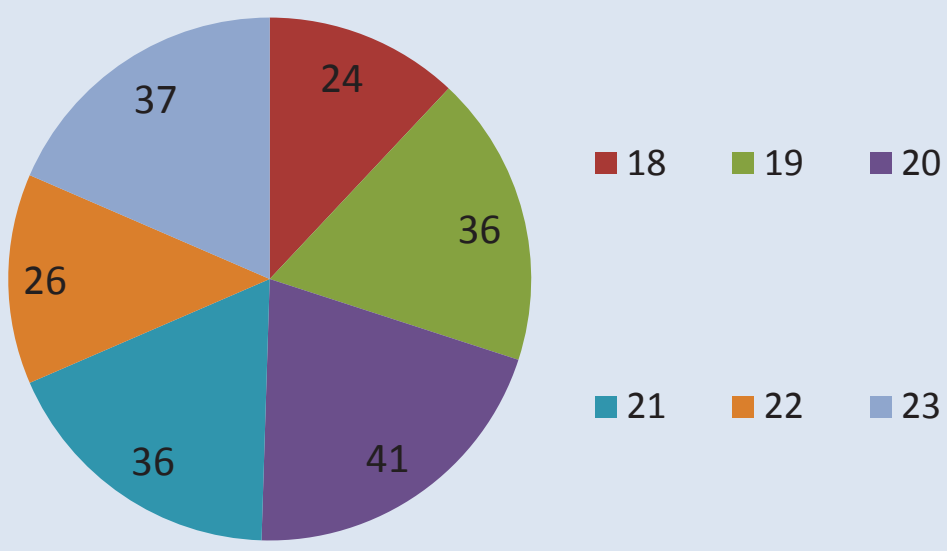

Chart 1

The BMI is a statistical measurement derived from our height and weight. Although it is considered to be a useful way to estimate healthy body weight, it does not measure the percentage of body fat. (Seagle HM, Strain GW, Makris A, Reeves RS, 2009). The BMI measurement can sometimes be misleading - a muscleman may have a high BMI but much less fat than an unfit person whose BMI is lower. However, in general, the BMI measurement can be a useful indicator for the 'average person'. 


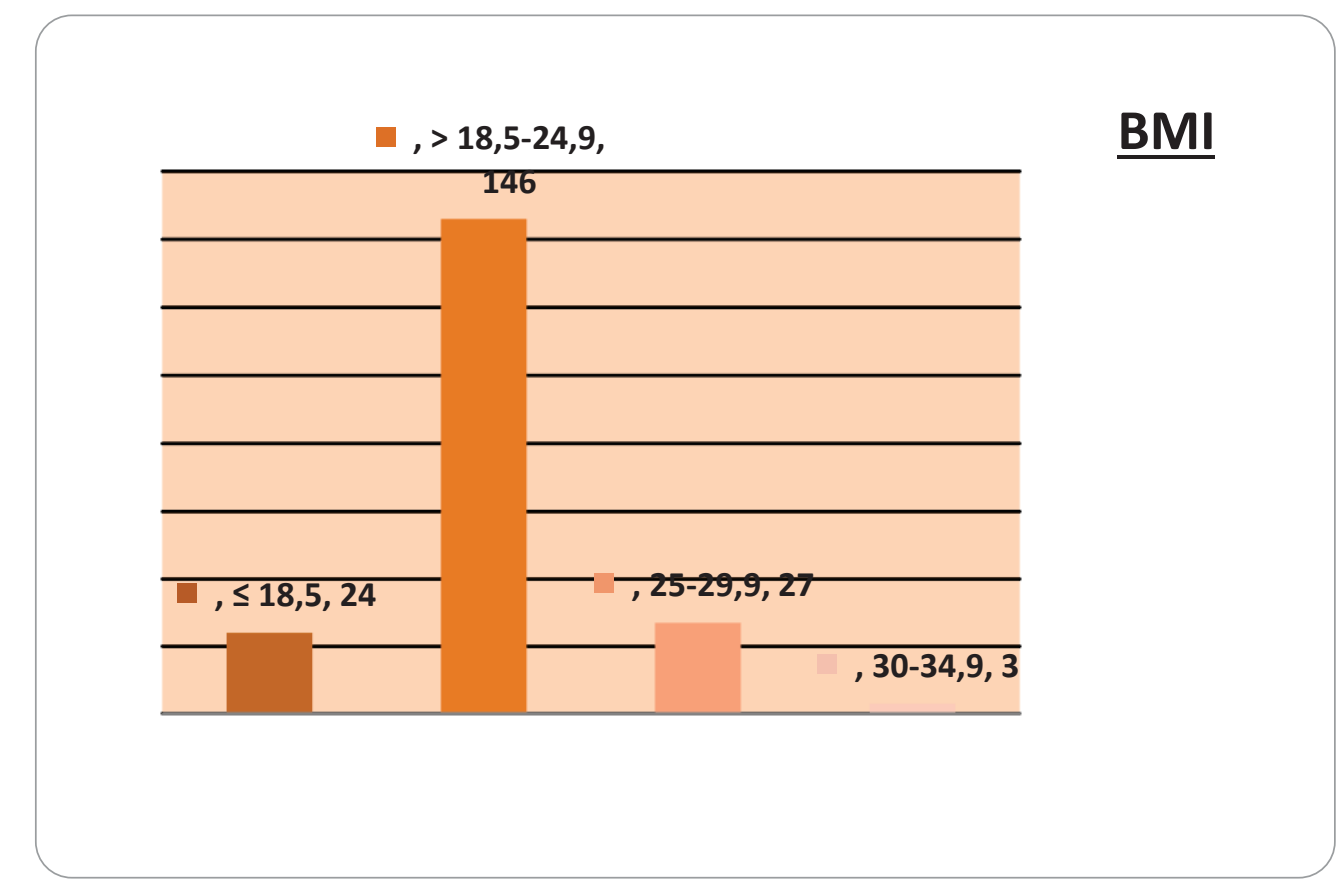

Graphic 1

\section{Procedure}

The method of measuring the BMI helped me to observe and study the obesity of 200 students. The analysis of the collected data led to these results: the value of BMI for $12 \%$ of the surveyed was lower or equal to 18,$5 ; 73 \%$ of them resulted to have a BMI varying from 18,5 to 24,$9 ; 13,5 \%$ of the students appeared to have 25 to 29,9 BMI value and only $1.5 \%$ of them resulted to have a value of 30 to $34,9 \mathrm{BMI}$.

Thus, about 140 subjects resulted to have normal BMI value and only 3 individuals were found to be obese. (Graphic 1). In this study the students were also asked about other reasons for consuming food despite being hungry, and it was noticed that 15 out of 200 students consumed food only when they were upset, 23 of them when being stressed, 35 students because of fatigue, 36 of them were for all the reasons above and 91 of them consumed just for being hungry. These results are presented in the following chart: (Chart 2) 


\section{Reasons for food consuming}

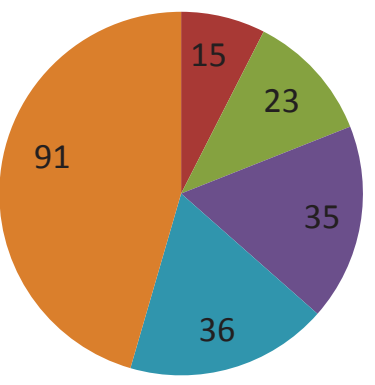

Being upset

Stress

Fatigue

All of them

None of them

Chart 2

\section{Obesity and eating frequency}

Eating frequency has become a fundamental component of most weight loss diets. Many of the current dietary plans have replaced the historical dietary recommendation to eat 3 large meals/d with a more frequent eating strategy that includes consuming smaller amounts of food every 2-3 h, 4-6 times/d. Increased eating frequency has been postulated to increase metabolism, reduce hunger and food cravings, improve glucose and insulin control and reduce body weight and body fat storage, making it an enticing dietary strategy for weight loss and/or the maintenance of a healthy body weight (Wadden TA, Volger S, Sarwer DB, 2011).

Graphic 2 presents the results about students eating frequency. From the data collected, it was concluded that 12 students consumed food every 2 hours; 79 out of 200 students consumed food every 4 hours and 109 students ate food every 6 hours. So, only a very small number of them ate more than 4 or 5 meals a day and $54,5 \%$ of students consumed no more than 3 meals a day. (Graphic 2).

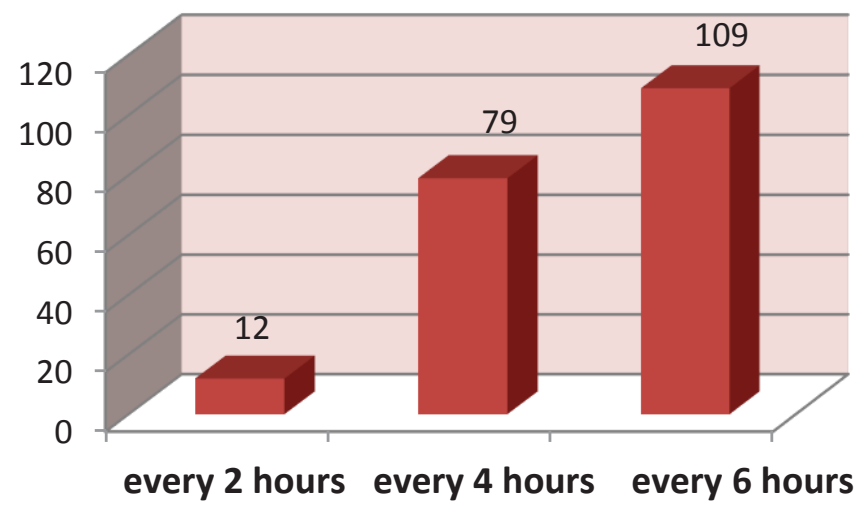

Eating frequency

Graphic 2 
Eating breakfast and its role in obesity is another point analyzed in this study. It is one of the most effective ways to stimulate our metabolism, have more energy, or lose weight. (Schurgin, S., and R. D.Siegel. 2003). Everyone should strive for an increased metabolism, which can be achieved through exercise and eating regularly (Aronne, L. J., and K. R. Segal. 2003). All the latest diets encourage 3 small meals a days with snacks in between to prevent cravings and binge eating (Bell, S. J., and G. K. Goodrick 2002).

The collected data indicated that 64 out of 200 surveyed subjects always consumed breakfast; 104 of them had breakfast sometimes and only 32 students never consumed breakfast. (Graphic3)

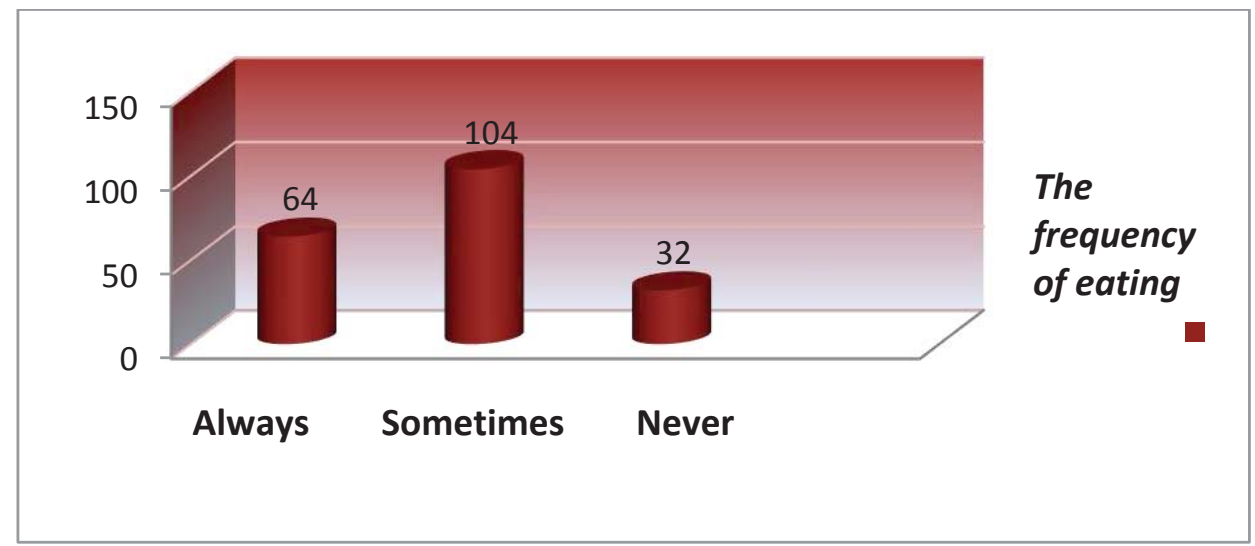

Graphic 3

The study also analyzed the latest time of the day for the last meal consumption and it was shown that for $65(32,5 \%)$ of the students the 21.00 o'clock was dinner consumption time and only 12 students consumed their dinner at 18.00 o'clock. The detailed figures about the distribution of the consumption meals time are presented in graphic 4.

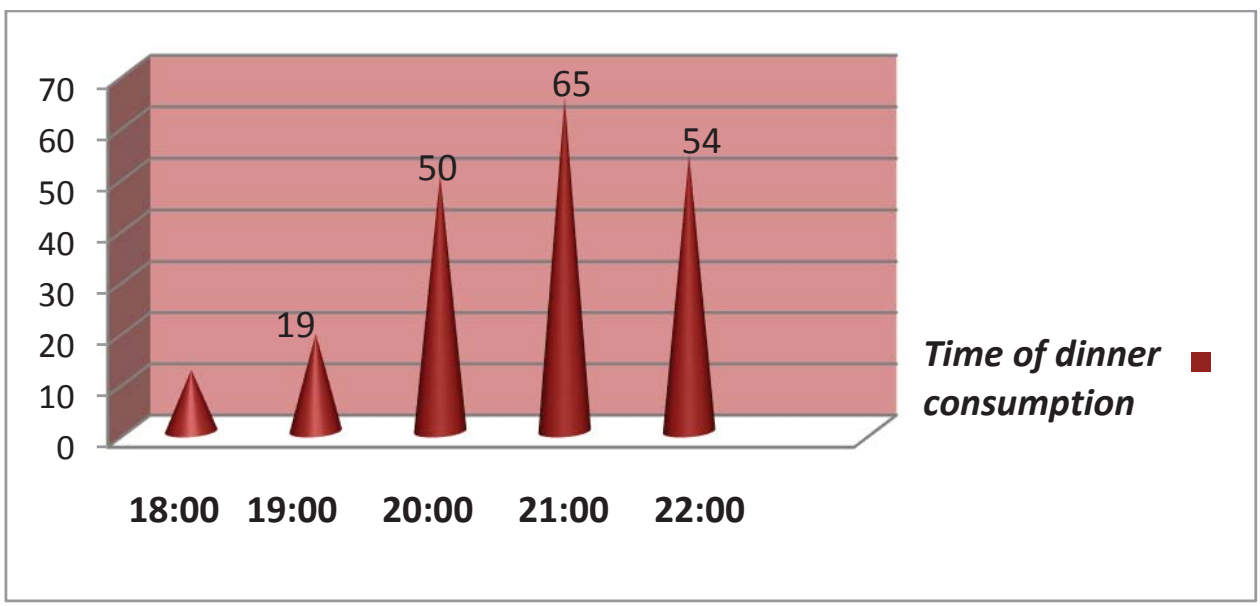

Graphic 4

With the arrival of televisions, computers, video games, remote controls, washing machines, dish washers and other modern convenience devices, the majority of people are leading a much more sedentary lifestyle compared to their 
parents and grandparents (Shekelle, P. G., M. L. Hardy, S. C. Morton, 2003). The less you move around, the fewer calories you burn. However, this is not only a question of calories. (Brudnak, M. A. 2002). Physical activity has an effect on how your hormones work, and hormones have an effect on how your body deals with food. (Colquitt, J., A. Clegg, M. Sidhu, and P. Royle, 2003).

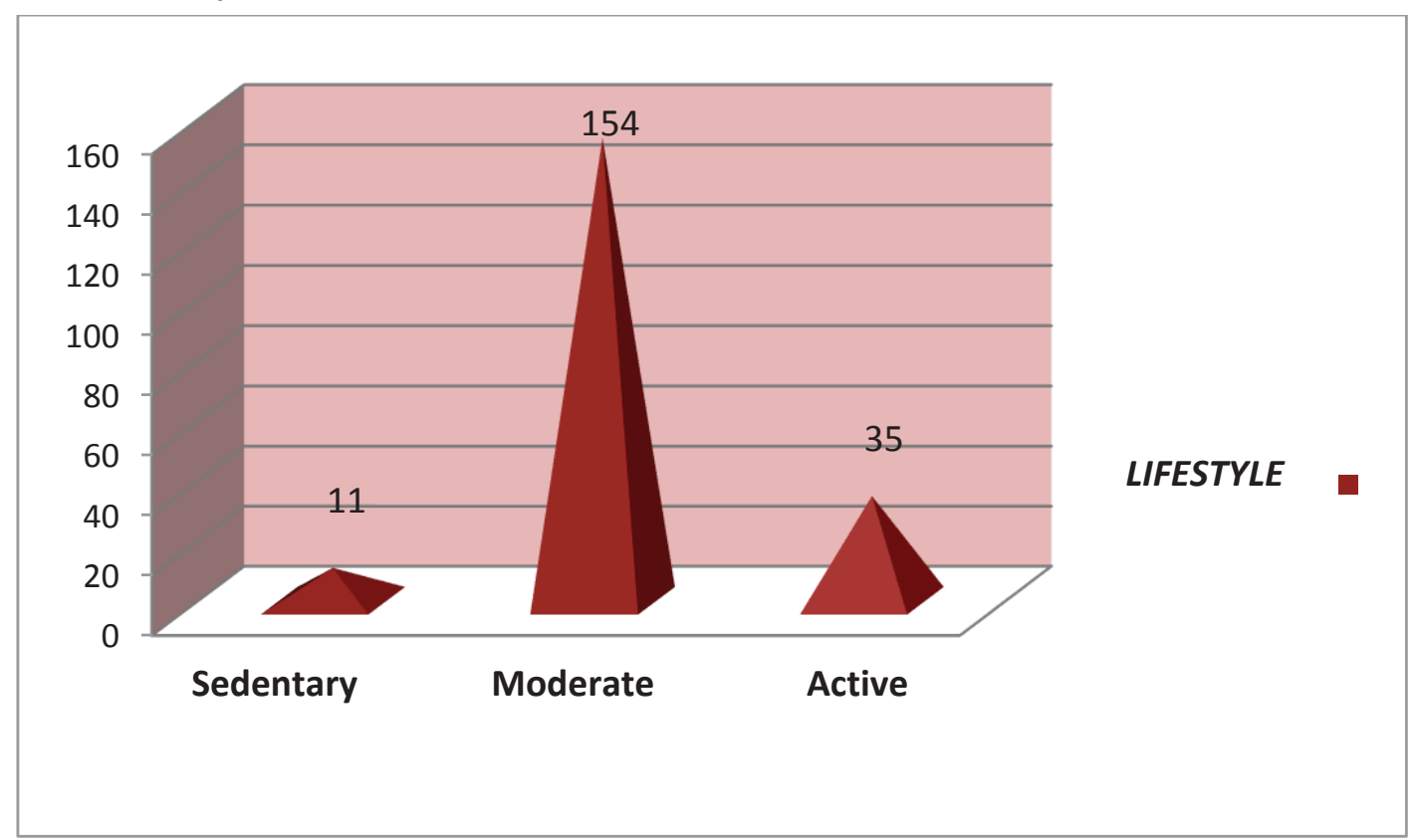

$\underline{\text { Graphic } 5}$

The subjects were also asked about their lifestyle and it resulted that 154 out of 200 students considered theirs a moderate lifestyle, i.e. their physical activity included only everyday walking. (Graphic 5)

\section{Results}

Obesity means having too much body fat. It is not the same as being overweight, which means weighing too much. A person may be overweight from extra muscle, bone or water, as well as from having too much fat (Pirozzo, S., C. Summerbell, C. Cameron, and P. Glasziou. 2002). According to the results, it was found that only $1,5 \%$ of the respondents were obese; $13,5 \%$ were overweight, $73 \%$ had a normal weight and $12 \%$ were underweight. None of them declared to suffer from any diseases and a total of $77 \%$ indicated to live a moderate lifestyle. As for the eating frequency, about half of the students $(54,5 \%)$ consumed no more than 3 meals a day and the latest hour for the last meal of the day was found to be the 21.00 o'clock.

This figure stands for $32,5 \%$ of the students. About breakfast eating frequency, it was found that it was not eaten regularly but only sometimes by a considerable number of students (104). It was clearly noticed that most of the Albanian students from the age of 18 to 23 were not suffering from obesity though they had little activity in their lifestyle.

\section{References}

Aronne, L. J., and K. R. Segal. (2003) "Weight Gain in the Treatment of Mood Disorders." Journal of Clinical Psychiatry 64, Supplement 8:22-29.

Bell, S. J., and G. K. Goodrick. (2002) "A Functional Food Product for the Management of Weight." Critical Reviews in Food Science and Nutrition 42: 163-178. 
Brudnak, M. A. (2002) "Weight-Loss Drugs and Supplements: Are There Safer Alternatives?"Medical Hypotheses 58:2833.

Colquitt, J., A. Clegg, M. Sidhu, and P. Royle. (2003) "Surgery for Morbid Obesity." Cochrane Database Systems Review: CD003641.

Dale KS, McAuley KA, Taylor RW, Williams SM, Farmer VL, Hansen P, et al. (2009), Determining optimal approaches for weight maintenance: a randomized controlled trial. CMAJ.180:E39-E46.]

Jensen MD. Obesity. In: Goldman L, Schafer Al, (2011) eds. Cecil Medicine. 24th ed. Philadelphia, Pa: Saunders Elsevier; chap 227.

Pirozzo, S., C. Summerbell, C. Cameron, and P. Glasziou. (2002) "Advice on Low-Fat Diets for Obesity (Cochrane Review)." Cochrane Database Systems Review: CD003640.

Schauer PR, Kashyap SR, Wolski K, et al. (2012) Bariatric surgery versus intensive medical therapy in obese patietns with diabetes. N Engl J Med.

Schurgin, S., and R. D. Siegel. (2003) "Pharmacotherapy of Obesity: An Update." Nutrition in Clinical Care 6: 27-37.

Seagle HM, Strain GW, Makris A, Reeves RS; (2009) American Dietetic Association. Position of the American Dietetic Association: weight management. J Am Diet Assoc. 109:330-346.

Shekelle, P. G., M. L. Hardy, S. C. Morton, et al. (2003) "Efficacy and Safety of Ephedra and Ephedrine for Weight Loss and Athletic Performance: A Meta-Analysis." Journal of the American Medical Association 289: 1537-1545.

Wadden TA, Volger S, Sarwer DB, et al. (2011) A two year randomized trial of obesity treatment in primary care practice. N Engl J Med. 365:1969-1979. 